\title{
Archetypical barriers to adapting water governance in river basins to climate change
}

\author{
CHRISTOPH OBERLACK* \\ Centre for Development and Environment, Universität Bern, Hallerstrasse 10, 3012 Bern, Switzerland \\ Institute of Geography, Universität Bern, Hallerstrasse 12, 3012 Bern, Switzerland \\ KLAUS EISENACK** \\ Resource Economics Group, Humboldt-Universität zu Berlin, Unter den Linden 6, 10099 Berlin, Germany
}

\begin{abstract}
Can we explain barriers to adaptation of collective action to changes in the natural environment? One reason for adaptation is the impacts of climate change. Ample case study evidence shows that such adaptation is rarely a smooth process. However, generalisable patterns of how and why barriers arise remain scarce. The study adopts a collective action perspective and the archetypes approach in a meta-analysis of 26 selected publications to explain how barriers arise in specific conditions. Focusing on adaptation of water governance in river basins, the study finds 21 reappearing patterns. Less well-established patterns relate to water property rights, hydrological standards, adaptation externalities, non-climatological uncertainty and vertical coordination. Results further show how barriers impede collective action in specific ways. The paper precisely introduces the archetypes approach, and shows that reported problems in adapting collective action under climate change arise from attributes of actors and pre-existing institutions rather than biophysical characteristics.
\end{abstract}

\section{Introduction}

Many river basins worldwide are affected by hydro-meteorological extremes, in particular floods and droughts. Commonly, various institutional arrangements are in place to deal with these disturbances through collective action. Climate change, however, will likely increase the frequency and intensity of heavy rain, floods and droughts in the coming decades, or has already increased them (IPCC 2013). This raises the question of whether existing water governance institutions are able to adapt to more frequent or intense extreme events. Evidence from case studies shows that this cannot be taken for granted (e.g. Milman et al. 2013; Pulwarty and Maia 2015), i.e. that there are barriers to climate adaptation. The literature on barriers to climate adaptation has taken stock of what kind

\footnotetext{
*Email: christoph.oberlack@cde.unibe.ch

**Email: klaus.eisenack@hu-berlin.de
} 
of barriers arise, but paid less attention to how and why they arise. Stronger emphasis on explaining the emergence of barriers to adaptation is needed to better inform strategies of dealing with them (Barnett et al. 2015; Biesbroek et al. 2013; Eisenack et al. 2014; Moser and Ekstrom 2010). Our paper presents a comparative institutional analysis of barriers to climate adaptation in river basins to extend understanding of how adaptation barriers arise. It is based on a meta-analysis of 26 systematically selected, coded and analysed empirical case studies.

Adaptation is defined here as individual or collective action that is ultimately intended to affect exposed units in response to expected or experienced climate change stimuli (Eisenack and Stecker 2012; Klein and Johula 2014). Barriers are impediments to specified adaptations for specified actors in their given context that arise from a condition or set of conditions. A barrier can be valued differently by different actors, and can, in principle, be reduced or overcome' (Eisenack et al. 2014: 868).

Current debate about the governance of climate adaptation shows that theoretical explanations for how and why barriers to adaptation emerge, persist and change over time are underdeveloped (Biesbroek et al. 2013; Eisenack et al. 2014; Huitema et al. 2016). Even though barriers identified so far point to crucial collective action problems (Bisaro and Hinkel 2016; Oberlack 2017), this literature is not yet strongly connected to institutional analysis. This is astonishing as climate change likely modifies interdependencies between actors, such as those between upstream and downstream water users or between water service providers, spatial planners and water users (Paavola 2007; Roggero 2015).

The 26 systematically selected publications of worldwide case studies in our meta-analysis are considerably heterogeneous in terms of river basins, contexts and reported variables. Such heterogeneity is well known in research on adaptation to climate change (Klein and Johula 2014). This raises the question of how to justify explanations of barriers to adaptation without making meaningless over-abstractions from particularities. Our paper thus aims to contribute to methodological developments in comparative institutional analysis by utilising the archetype approach (Eisenack et al. 2006) to analyse recurrent patterns of adaptation barriers. The results show that 21 recurrent kinds of collective action problems explain the emergence of barriers.

These archetypes qualify common statements from the literature. While our paper reconfirms some well-known barriers, it cannot support some of the 'usual suspects', and it characterises others that are not so much researched yet, but invite more institutional analysis, e.g. barriers from specific water rights allocation, from hydrological standards or from externalities caused by adaptation actions.

The results provide insights beyond climate adaptation, namely on established typologies from the institutional theory of common-pool resource governance 
(CPRs). Such typologies consider how biophysical characteristics of the CPR give rise to collective action problems (Ostrom et al. 1994; called 'realist-materialist position' by Bisaro and Hinkel 2016). A diversity of institutions enables resource users to solve collective action dilemmas in dealing with their biophysical environment (Ostrom 2005). What does this imply for the emergent collective action problems if the biophysical environment (e.g. the climate) changes? Does the way in which biophysical conditions change (e.g. more frequent floods or droughts) explain the kind of barriers to adaptation that emerge? Based on the evidence from the 26 case studies, the results of our paper suggest that problems in adapting collective action under climate change arise primarily from particular features of pre-existing institutions and actor attributes.

The remainder of the paper is organised as follows. Section 2 reviews climate change adaptation in river basins from the perspective of CPR theory with regard to the governance of collective action problems. Section 3 introduces the archetypes approach with a novel set-theoretic definition. It also describes the methods and material. Section 4 presents the results. Section 5 discusses the contributions of this paper to CPR theory and adaptation research and section 6 concludes.

\section{Collective action and adaptation to climate change in river basins}

Because water is an essential good that provides multiple services, and because water is mobile in space and variable in time, it is costly to organise responses to water scarcity during droughts or excess water during floods. Users of water services are typically highly interdependent, for example through upstreamdownstream relations. By interdependence we mean any kind of influence that a choice or reward of one actor can have on another, be it through institutional or biophysical links (Paavola 2007). Governance of resource access under climate change, e.g. through property rights regimes, is hence not straightforward.

In fact, many empirical studies report barriers to adaptation in river basins and other units exposed to climate change. Scholars have started collecting and systematising barriers (e.g. Biesbroek et al. 2011; Eisenack et al. 2011; Moser and Ekstrom 2010). This is important work to build upon, but it offers, up to now, little explanation 'of the reasons why adaptation is proceeding more slowly than the growing urgency of climate change would lead us to expect' (Eisenack et al. 2014: 870; see also Barnett et al. 2015; Biesbroek et al. 2013). For adaptation in river basins, existing studies show that climate change typically affects different water services - such as navigation, drinking water, hydropower and fishing. Well-established results are the benefits of participatory water resources management, and the challenges from climate change uncertainty (e.g. Huntjens et al. 2012, Pahl-Wostl and Knieper 2014).

While there is little institutional analysis of barriers to adaptation, there is considerable work on water governance (e.g. Garrick et al. 2013; Libecap 2011; 
Ostrom 1990; Saleth and Dinar 2008). Our study aims to go one step further in deepening the understanding of barriers to adaptation in that direction. The more general literature on water governance has shown the importance of factors such as polycentric institutions and cross-scale institutional linkages (Heikkila et al. 2011; Pahl-Wostl and Knieper 2014; Saleth and Dinar 2008), adaptive capacity (Milman et al. 2013), water allocation rules (Schlager and Heikkila 2011), devolution (Blomquist et al. 2005), policy learning (Huntjens et al. 2012), sustained stakeholder participation (Blomquist et al. 2005), clear boundaries and enforcement (Villamayor-Tomas et al. 2015), human pressure on water use (Knieper and Pahl-Wostl 2016) and recognition of local narratives and historical meanings of the rivers (Ching and Mukherjee 2015). These factors increase the likelihood that governance systems can cope with collective action problems that would lead to overuse or inequality in governing water in river basins. The literature cautions against panaceas (Meinzen-Dick 2007) and urges researchers and policymakers alike to recognise the diversity of contexts (Ostrom et al. 2007).

In terms of collective action problems in natural resource governance, CPR theory conventionally distinguishes appropriation dilemmas and provision dilemmas (Ostrom et al. 1994). Appropriation problems describe the social dilemma structure, which arises from the incentives of individual resource users to appropriate resource units beyond levels that would be rational from the collective perspective of a user community. As Ostrom et al. (1994) show, the precise structure of incentives in appropriation dilemmas varies with biophysical factors, in particular with the (a)symmetry of appropriation externalities between resource users, with the nature of technological externalities and with the spatial distribution of resource units (Janssen and Rollins 2012; Ostrom and Gardner 1993). By contrast, provision dilemmas relate to the free-rider incentives for resource users when they decide about their contributions to create or maintain a resource stock, including its physical infrastructure. The precise structure of provision problems varies with the time-dependence of supply- and demand-side strategies (Ostrom et al. 1994).

Such typologies of governance problems are essential for institutional diagnostics, among other reasons (Cox 2011; Ostrom et al. 2007; Young 2002). A diagnostic approach seeks to match particular features of institutions to the particular features of governance problems that arise in specific social-ecological conditions (Cox et al. 2010). An important motivation for advancing diagnostic methods is to build cumulative knowledge on such matches (Cox 2011; Ostrom 2009). This literature has put much emphasis on biophysical conditions (e.g. upstream-downstream relations and infrastructure) to explain what arrangements for collective action emerge. In an important diagnostic example for applying CPR theory to climate adaptation, Bisaro and Hinkel (2016: 354) analyse, based on theoretical arguments, 'how biophysical conditions give rise to certain types of social dilemmas' in adaptation governance. If the biophysical 
conditions change due to global warming, one would expect new or modified social dilemmas (see Eisenack 2016 for a similar argument). Since adapting institutional arrangements to modified dilemmas requires, in turn, collective action, it can thus be expected that the characteristics of biophysical change give rise to certain types of barriers to adaptation. We will investigate the validity of this general proposition in our sample of cases.

\section{Archetypes and methods}

\section{Archetypes approach}

Recent literature on climate adaptation shows substantial heterogeneity in the local or regional cases, where barriers are reported, and in their biophysical, socio-economic and institutional contexts (Eisenack et al. 2014). This raises the methodological question of whether and how to systematically identify generalisable patterns, if general regularities that apply to all cases cannot be expected. This is a challenge to research on climate adaptation, but is also well known in other research fields (Ostrom et al. 2007; Petschel-Held 2003; Rittel and Webber 1973; Warren 2002). One strategy would be an idiographic approach that considers each case as unique. This would avoid making wrong generalisations, but would also impede the transfer of knowledge and effective governance strategies between cases. By contrast, a nomothetic strategy, aiming at generally applicable explanations for all cases, would likely lead to over-generalisations and ineffective policy panaceas if contexts are highly heterogeneous (Frey and Cox 2015).

We thus employ an approach in between these two extremes to identify reappearing patterns, called archetypes (Eisenack et al. 2006, Oberlack and Eisenack 2014; UNEP 2007). Archetypes are recurrent patterns of basic interactions in social-ecological systems. They are building blocks of socialecological interaction that reappear in multiple cases. Archetypes are described as building blocks because it is not required that every case can be completely described by a single archetype. One archetype hence covers the universe of considered cases only partially. For a comprehensive picture of a single case it might be necessary to combine several archetypes and their casespecific particularities, i.e. the specific values and meaning of abstract variables. Archetypes are described abstractly enough to cover relevant properties of multiple cases, but should not be so abstract so that they apply to every case which would make them meaningless (Eisenack 2012; Oberlack et al. 2016).

To illustrate this with a simple example, consider constrained public budgets. While they are a frequently reported barrier to adaptation, constrained budgets are not always the primary problem - obviously, they are not present in all cases. In other cases, constrained budgets might occur in different combinations with other features, such as externalities that lead to inefficient spending, or limited governmental incentives to provide sufficient budgets. 
There are several related approaches: (1) The diagnostic approach to human-environment interactions and social-ecological systems starts from the assumption that there are no general institutional fixes to all kinds of environmental problems (Ostrom et al. 2007; Young 2002). (2) The syndrome approach to global change was inspired by a medical metaphor, too (Lüdeke et al. 2004; WBGU 1994). Each of the 16 identified syndromes represents a specific functional pattern of abstract factors that is more or less relevant under different conditions. The factors allow for both comparison between cases and for case-specific concretisation. Multiple syndromes can occur in the same case. The institutional dimension is strongly under-represented in this approach. (3) Similarly, the vulnerability of human-environment systems to environmental and socio-economic change has been synthesised along socalled archetypes of vulnerability (Kok et al. 2016; Sietz et al. 2011; UNEP 2007). Reappearing configurations are decomposed into subsets of mutually exclusive vulnerability profiles. They describe the specific conditions that create vulnerability for specific groups of people. Policy suggestions are specific for each vulnerability profile. (4) The social-ecological systems (SES) framework of Ostrom (2009) provides a set of variables that empirical research over the past three decades has shown to matter for sustainability of SESs. Its multi-tiered structure (i.e. higher-tier variables are sub-classes of lower-tier variables) allows the researcher to select the level of abstraction most appropriate for a specific study.

In our paper, we adopt a set-theoretic understanding of archetypes. This understanding allows for a precise expression of the approach, and lends to using set-theoretic methods. Alternative expositions are more qualitative (e.g. Eisenack et al. 2006; Oberlack and Eisenack 2014), or are based on quantitative indicators (e.g. UNEP 2007; Kok et al. 2016). The universe of analysed cases is denoted as the case set $C$. The considered set of attributes is denoted by $A$. Putting aside the empirical difficulties in this section, every attribute $a \in A$ is defined in such a way that it can be assessed whether it holds for a specific case $c$ $\in C$. The complete data are thus a relation $K \subseteq C \times A$. A whole set of attributes $A^{\prime} \subseteq A$ bolds for a case $c \in C$, if all attributes $a^{\prime} \in A^{\prime}$ hold for $c$. It is further useful to distinguish two types of attributes. First, diagnostic attributes $D \subseteq A$ characterise institutional, biophysical, technical and socio-economic conditions of the cases. They characterise any event, factor or change that characterises the considered social-ecological system(s) or explains an outcome in a case $c$. Second, outcome attributes $F \subseteq A$ characterise present or expected conditions that are to be explained by diagnostic attributes, variables that express a prediction for a case, or performance indicators for evaluation (depending on the research question). The present study keeps the outcome attributes $F$ quite simple - there is only one: the occurrence of a barrier to adaptation. The more challenging task is to specify a set of diagnostic attributes $D$ that is meaningful in terms both of theory, and of the cases we study. 
An archetype is defined as a recurrent, specific relation between diagnostic and outcome attributes of the form:

For all cases $c$ of a subset $C_{i} \subseteq C$ : if a set of the diagnostic attributes $D_{i} \subseteq D$ holds for $c$, then the outcome attributes $F_{i} \subseteq F$ are expected to hold for $c$.

The index $i$ of the subsets is needed to allow for multiple archetypes to hold in one case. An archetype is 'recurrent' if it is observed in two or more cases. It is said that an archetype $i$ covers a case $c$ if $c \in C_{i}$ and the diagnostic attributes $D_{i}$ and the outcome attributes $F_{i}$ hold for $c$. Thus, single cases can be related to archetypes that cover them, thereby identifying those aspects of individual cases that are reappearing, while identifying idiosyncratic aspects that make cases unique.

Not all arbitrary combination of diagnostic and outcome attributes can qualify as an archetype. We further require them to have a certain feature according to formal concept analysis (Ganter and Wille 1999) as follows. The set of all cases in the data that have a single attribute in common is called the attribute's extension. The extension of a set of multiple attributes contains the set-theoretic intersection of all the single attributes' extensions (i.e. all cases that share at least all these multiple attributes). The extension is similar to what other approaches to meta-analysis call the frequency of an attribute combination (e.g. Sietz and Van Dijk 2015). Symmetrically, the intension of a set of cases is the intersection of their attributes (i.e. the attributes that are shared by all cases in the set). An archetype requires a 'closure', meaning that the extension of its attributes, a set of cases, has exactly their intension as shared attributes. A 'closure' can be computed with modern algorithms (Ganter and Wille 1999), and guarantees that an archetype covers a maximum set of cases with joint attributes, and that it covers a maximum set of attributes that are shared by this set of cases (see Supplementary Material for a stylised example at https://www. resource-economics.hu-berlin.de/publiccodebook/at_download/file). If such a set of archetypical barriers to adaptation is developed, we can identify cases with similar adaptation challenges.

For example, we might expect that upstream-downstream externalities give rise to a barrier to adapt water governance to climate change. Externalities are likely to lead to water use conflicts, as upstream users might have little incentives to reduce water consumption during droughts. So, let the case set $C$ comprise all reported statements about barriers, and the set $C_{1} \subseteq C$ the statements from cases where droughts are expected to become more frequent due to climate change. Then, the diagnostic attribute 'upstream and downstream users present' (denoted by $\left.a_{1}\right)$ together with the attribute 'water use conflicts' $\left(a_{2}\right)$ might explain barriers in some cases. However, this might not generally be sufficient for a barrier. Some studies may report both the attribute $a_{1}$ and a barrier, but not $a_{2}$, due to 'collective choice arrangements for water distribution' (diagnostic attribute $a_{3}$ ). Finally, there might be a subset of cases $C_{2} \subseteq C$ with droughts playing no role at 
all. Thus, we a have a set of two archetypes in this example. The first is given by $C_{1}, D_{1}=\left\{a_{1}, a_{2}\right\}, F=\{$ barrier $\}$, the second by $C_{1}, D_{2}=\left\{a_{1}, a_{3}\right\}, F=\{$ barrier $\}$, while in $C_{2}$ the explanations of the first archetype are just not applicable. Note that there might be cases $c \in C_{1}$ where both archetypes hold.

\section{Method: Model-centred meta-analysis}

\section{Retrieval and selection of case studies}

The primary studies for this meta-analysis (see Rudel 2008) were retrieved through keyword search in Web of Science (WoS) and Scopus. Using the keywords "climat* change OR global warming) AND (adapt* AND river AND (barrier* OR constraint* OR limit* OR opportunit* OR decision-making OR governance OR capacity))', we retrieved 628 references in WoS and 573 references in Scopus published since 1990 (last accessed 3 June 2015), yielding a total of 828 unique publications.

We subsequently excluded those studies that did not meet the following inclusion criteria, applied first to titles and abstracts (leaving 166 papers), and then to full texts: Studies must be based on primary data (thus excluding reviews or conceptual papers), and they must be peer-reviewed. Methodologically, the research process must be transparent with regard to data sources, conceptual and theoretical approach. Studies must analyse intentional climate change adaptation options for water governance in parts of a river basin. Finally, studies must provide a thorough analysis of collective decision making and barriers that impede adaptation. This procedure yielded 26 publications that meet all inclusion criteria (see appendix for references, river basins and diagnosed archetypes).

\section{Coding}

We went through these publications line by line to identify text segments where the authors make statements about causal effects found in their primary studies. We call each such text segment a model. Models are hence the analytical units in this meta-analysis. To qualify for a model, a text segment must be based on the authors' empirical research. We excluded segments that only report insights from other work (cited in their publications), and segments that are obviously more speculative or are framed as hypothesis for future work (frequently in the conclusions sections). The identified text segments typically have a length of about one paragraph (sometimes down to a sentence, e.g. 'the length of hydropower concessions (up to 80 years) mean that windows of opportunity for revision seldom appear', Hill 2013). Sometimes, models are not expressed in one connected segment, but distributed over different segments or make reference to contextual conditions in other parts of the text. In such cases, these textually separated but logically connected segments were coded as one model. We coded the texts by using the software MaxQDA. Inter-coder reliability of coded models was achieved in two steps. First, five publications were 
double-coded independently by both authors, with an inter-coder reliability of $62 \%$. Discrepancies were resolved in discussion. Second, each author coded about one half of the publications. The identified models were then checked by the other author and removed if both did not agree $(76 \%$ of the models remained). In the end, we identified 114 models (range: 1-12 models per publication).

We started from Ostrom's (2009) SES framework as the analytical framework for our codebook. It explains outcomes $(\mathrm{O})$ as a result of interactions (I) in action situations that are shaped by the attributes of four main components of social-ecological systems (first-tier variables): attributes of the governance system (GS), actors (A), resource system (RS) and resource units (RU). An SES is embedded in broader political, social and economic setting (S) and related to other ecosystems (ECO). We needed to modify the SES framework in order to code reported case study evidence adequately. First, we decomposed the GS-component for adaptation situations according to Oberlack (2017). Second, for the I-component it proved useful to distinguish five variables to characterise how barriers impede adaptation decision making. Barriers can relate to 'constrained capacity' (actors have limited action space for adaptation, Berkhout et al. 2006); 'insufficient reason' (insufficient reason to prioritise adaptation among alternative actions, Bromley 2006; Vatn 2005); 'high transaction costs' of collective action (Williamson 2010); 'asymmetric control' of actors over collective outcomes (Ostrom 2005; Schmid 2004); and 'stalled social learning' (regular knowledge exchange and updated information is not accessible or used (Naess et al. 2005, Pahl-Wostl 2009). Finally, it proved useful to introduce the category 'adaptation option (AO)' to characterise the main attributes of the adaptation considered in a case, such as the time-scale of implementing an $\mathrm{AO}$ or the externalities associated with an AO.

We coded the models by second- and third-tier attributes of the adjusted SES framework, using at least one interaction attribute (I) and at least one GS-, A-, RS-, RU-, AO-, S- or ECO-attribute. In the parlance of section 2, the diagnostic attributes $D$ take the form of I-, GS-, A-, RS-, RU-, AO-, S- or ECO-attributes, while the outcome attribute $O$ is the occurrence of an adaptation barrier. The set $C$ is the list of all models.

A detailed codebook of second-tier (e.g. GS24: property rights; AO3: time requirement to implement the adaptation option) and third-tier (e.g. GS241a: secure water property rights with fixed allocations; RS221: floods are climate change stimuli) attributes was inductively developed and continuously refined by stepwise coding of case studies. The primary studies were coded by both authors separately. The initial five studies were double-coded with an inter-coder reliability of $62 \%$. Subsequently, coded models and proposed modifications of the codebook were discussed regularly (i.e. after coding 4-5 additional studies) to ensure consistent coding. In a final round, all models were recoded using the final codebook, which is available in the Supplementary Material 
(https://www.resource-economics.hu-berlin.de/publiccodebook/at_download/ file). Remaining interpretive differences were resolved through discussions. Codings of attributes were removed if they were not assigned by both authors $(24 \%)$. The obtained data set is a table of 114 models and 95 attributes.

\section{Data analysis}

First, we performed a formal concept analysis (FCA) (Ganter and Wille 1999) with the Concept Explorer software to obtain the archetypes. Alternatively, we might have used the similar Qualitative Comparative Analysis (Ragin 1987; Schneider and Wagemann 2012) or purely qualitative approaches. We opted for FCA because the algorithm can determine automatically the closure property of archetypes (see above) and can deal flexibly with data gaps.

A configuration of at least two diagnostic attributes that lead to a barrier in a model qualifies as an archetype, if (1) its extension contains at least three models from at least two papers, and (2) one of the attributes is an I-attribute. This ensures that archetypes are based on multiple cases and sources. Some models are covered by multiple archetypes (when their extensions have pairwise non-empty intersections), i.e. they are building blocks. If we found configurations of more than two diagnostic attributes it was sufficient for an archetype to occur in two models from two papers. This procedure typically yields subtypes. A subtype's extension is a strict subset of the more 'coarse-grained' archetype defined by two attributes, and contains models with additional attributes in common. The requirement of archetypes to reappear led to 12 of 114 models not being covered by any archetype. These models might be interesting for further investigation, which is beyond the scope of this paper.

Second, to obtain more overview, we clustered the archetypes by similarity in terms of collective action problems, following a parallel strategy. One author adopted a grounded theory approach and inspected all models individually drawing on the original texts of the primary studies. This author clustered them by similarity with regard to the collective action problem through which their diagnostic attributes generate barriers. The other author inspected the identified archetypes and clustered them according to common problems. It turned out be helpful to distinguish operators and receptors of adaptation (Eisenack and Stecker 2012). Operators are actors who have agency in planning or implementing adaptation actions. Receptors are human or organisational actors who are affected by an adaptation action. These include beneficiaries (Tompkins and Eakin 2012) and other affected actors. Both authors discussed their individual clustering to achieve inter-subjective agreement. Discussion was guided by the criteria: (1) theoretical consistency within a collective action problem and (2) small numbers of problems. The clustering procedure was performed until both authors converged. One might expect that clustering yields more abstract 'super-archetypes'. Note that this is not necessarily the case, since clusters collect archetypes by theoretical similarity. According to the definition 
in this paper, an archetype requires more: shared attributes need to hold for all models covered by it (see below that this indeed the case for our archetypes, but not for the clusters).

\section{Collective action problems in adapting water governance systems}

The results show that adaptation of water governance systems in river basins to climate change is hampered by a set of archetypical barriers that can be summarised as coordination gaps, path dependencies, zero-sum games, uncertainty, competing priorities and tangible constraints. Table 1 shows the details of the 21 identified archetypes. They cover $89 \%$ of the models and all primary studies. The text below describes each of the collective action problems by cluster and illustrates them with case examples.

\section{Coordination gaps among interdependent operators}

An example for a coordination gap is found in South Saskatchewan River Basin of western Canada. A multitude of state and non-state water organisations with partly overlapping mandates and functions combined with limited coordination devices has led to communication chasms and a need for local communities and business to deal with a multitude of organisation with unclear responsibilities (Hurlbert and Diaz 2013).

Coordination gaps among interdependent operators of adaptation are the most frequently observed collective action problems in our sample. All five archetypes have two components. First, pre-existing institutional arrangements scatter responsibilities for water governance among multiple operators, but the institutionalised mechanisms for their vertical and/or horizontal coordination are limited or absent. The second necessary component of coordination gaps is that the considered adaptation actions involve strong interdependency between operators of the adaptations. This can be due for instance to upstreamdownstream water flows, rivalry for water service consumption or established institutional hierarchies.

This combination of institutional fragmentation and strong actor interdependency creates barriers in adaptation governance processes mainly through high transaction costs. High transaction action costs provide adverse incentives for operators to plan or implement those adaptation actions for which they must rely on interagency coordination. The transaction costs can stem, for instance, from time-consuming negotiations, and lead to the absence of social interaction on planned adaptation. The difficulty in overcoming coordination gaps increases with the degree to which actor interests are heterogeneous and incompatible. Similarly, coordination needs rise if trust among actors is limited, necessitating the negotiation of more complete contractual arrangements.

An interesting special case is archetype 1.5 in which a potential operator of adaptation would be willing to adapt, but is hampered from doing so because 
Table 1. Archetypical barriers to adapting water governance systems in river basins to climate change

\begin{tabular}{|c|c|c|c|c|}
\hline AT \# & Description of archetype & No. of models & No. of studies & Codes \\
\hline \multicolumn{5}{|c|}{ Coordination gaps among interdependent operators (32 models) } \\
\hline \multirow[t]{2}{*}{1.1} & High transaction costs due to scattered responsibilities & 8 & 8 & I3-GS21 \\
\hline & High transaction costs due to scattered responsibilities and limited horizontal coordination & 2 & 2 & I3-GS21-GS42 \\
\hline \multirow[t]{2}{*}{1.2} & High transaction costs due to limited horizontal coordination & 7 & 7 & I3-GS42 \\
\hline & $\begin{array}{l}\text { High transaction costs due to limited horizontal coordination with heterogenous interests } \\
\text { and upstream-downstream externalities }\end{array}$ & 2 & 2 & I3-GS42-A22-RS12 \\
\hline \multirow[t]{2}{*}{1.3} & High transaction costs due to limited vertical coordination & 3 & 3 & I3-GS41 \\
\hline & Insufficient reason due to limited vertical coordination & 3 & 3 & I1-GS41 \\
\hline \multirow[t]{2}{*}{1.4} & High transaction costs due to limited trust & 6 & 6 & $\mathrm{I} 3-\mathrm{A} 25$ \\
\hline & High transaction costs due to limited trust and concurrent stimuli & 2 & 2 & I3-A25-RS5 \\
\hline 1.5 & Limited control of operator due to limited control in polycentric system & 4 & 4 & I4-GS31 \\
\hline \multicolumn{5}{|c|}{ Path dependencies (25 models) } \\
\hline 2.1 & High transaction costs due to secure property rights with fixed allocations & 5 & 3 & I3-GS241a \\
\hline \multirow{3}{*}{2.2} & $\begin{array}{l}\text { Stalled social learning due to rules based on historical hydrology and limited understanding } \\
\text { of climatic stimulus }\end{array}$ & 3 & 2 & I5-GS234b-A13 \\
\hline & $\begin{array}{l}\text { Stalled social learning (lagged information uptake) due to rules based on historical } \\
\text { hydrology and limited understanding of climatic stimulus and of SES }\end{array}$ & 2 & 2 & I5-GS234b-A13-A12 \\
\hline & Limited understanding of climatic stimulus and rules based on historical hydrology & 4 & 3 & A13-GS234b \\
\hline 2.3 & Stalled social learning due to slow procedures for institutional change & 3 & 3 & I5-GS91 \\
\hline \multirow[t]{2}{*}{2.4} & Insufficient reason due to path dependency in agency & 3 & 3 & I1-A16 \\
\hline & High transaction costs due to path dependency in agency & 3 & 3 & I3-A16 \\
\hline \multicolumn{5}{|c|}{ Zero-sum games (24 models) } \\
\hline \multirow[t]{3}{*}{3.1} & High transaction costs due to heterogenous interests about water services & 14 & 9 & $\mathrm{I} 3-\mathrm{A} 22$ \\
\hline & Insufficient reason due to heterogenous interests about water services & 6 & 5 & I1-A22 \\
\hline & $\begin{array}{l}\text { Insufficient reason due to heterogenous interests about water services and high costs of } \\
\text { adaptation }\end{array}$ & 2 & 2 & $\mathrm{I} 1-\mathrm{A} 22-\mathrm{AO} 4$ \\
\hline 3.2 & High transaction costs due to externalities of the adaptation option & 5 & 5 & I3-AO1 \\
\hline
\end{tabular}


Table 1. (Continued)

\begin{tabular}{|c|c|c|c|c|}
\hline AT \# & Description of archetype & No. of models & No. of studies & Codes \\
\hline & $\begin{array}{l}\text { High transaction costs (costs of conflict) due to adaptation externality and } \\
\text { top-down-decision-making }\end{array}$ & 2 & 2 & I3-AO1-GS44 \\
\hline & $\begin{array}{l}\text { High transaction costs due to adaptation externality and uncertain consequences of the } \\
\text { adaptation option }\end{array}$ & 2 & 2 & I3-AO1-AO2 \\
\hline & Co-occurrence of heterogenous interests about water services and adaptation externality & 4 & 4 & $\mathrm{~A} 22-\mathrm{AO} 1$ \\
\hline \multicolumn{5}{|c|}{ Uncertainty (21 models) } \\
\hline \multirow[t]{3}{*}{4.1} & Constrained capacity due to limited understanding of SES & 5 & 4 & I2-A12 \\
\hline & High transaction costs due to limited understanding of SES & 5 & 4 & I3-A12 \\
\hline & Stalled social learning due to limited understanding of SES & 4 & 4 & I5-A12 \\
\hline \multirow[t]{3}{*}{4.2} & Constrained capacity due to limited understanding of climatic stimulus & 4 & 3 & I2-A13 \\
\hline & Insufficient reason due to limited understanding of climatic stimulus & 3 & 3 & I1-A13 \\
\hline & Co-occurrence of limited understanding of SES and of climatic stimulus & 3 & 3 & A12-A13 \\
\hline \multicolumn{5}{|c|}{ Competing priorities (20 models) } \\
\hline 5.1 & Insufficient reason due to incompatible institutional incentives & 6 & 4 & I1-GS23 \\
\hline 5.2 & Insufficient reason due to concurrent stimuli & 4 & 3 & I1-RS5 \\
\hline 5.3 & Insufficient reason due to limited awareness of climate change & 5 & 4 & I1-A111 \\
\hline 5.4 & Insufficient reason due to perception of climate change as a future problem & 3 & 3 & I1-A15 \\
\hline 5.5 & Insufficient reason due to heterogeneous interests about priority of adaptation & 5 & 3 & I1-A23 \\
\hline \multicolumn{5}{|c|}{ Tangible constraints (19 models) } \\
\hline \multirow[t]{5}{*}{6.1} & Constrained capacity due to financial constraints & 9 & 8 & I2-A31 \\
\hline & $\begin{array}{l}\text { Constrained capacity due to financial constraints in the presence of an existing adaptation } \\
\text { deficits }\end{array}$ & 2 & 2 & I2-A31-RS6 \\
\hline & Constrained capacity due to financial constraints and poor coordination of data & 2 & 2 & I2-A31-GS421 \\
\hline & Constrained capacity and high transaction costs due to financial constraints & 3 & 2 & I2-I3-A31 \\
\hline & Co-occurrence of financial constraints and limited understanding of SES & 3 & 2 & A31-A12 \\
\hline 6.2 & Constrained capacity due to limited information & 4 & 4 & I2-A41 \\
\hline 6.3 & Constrained capacity due to staff constraints & 4 & 3 & I2-A51 \\
\hline
\end{tabular}

Note. Frequency counts have no meaning in terms of significance in our methodology, and one model can contain one or more archetypes. The table contains one row per archetype, sorted by the collective action problems, each described in more detail in this section. For each archetype (with a two-digit number in the left-hand column) a short description is provided based on the codes that define it. Subtypes of archetypes are presented in separate rows, and do not carry an individual number. 
control over decision making is located elsewhere in a polycentric system. For instance, Farley et al. (2011) show how a municipal department in Oregon, USA, was willing to adapt water quality standards to new climatic conditions, but was constrained by the state-level regulatory framework, without an effective option for intervening at this higher level.

\section{Path dependency in climate change adaptation}

Attention to the role of path dependency in climate adaptation is increasing (Barnett et al. 2015). Path dependency describes situations in which institutions, infrastructures or practices that have been established in the past constrain opportunity sets, shape beliefs or preferences in current decision making (Garrelts and Lange 2011).

We find four archetypes. First, secure water rights with a fixed quantity of water withdrawal have impeded climate adaptation. In arid areas that have been colonised in the past such as in Australia and the Western US, it was crucial to incentivise the construction of new irrigation systems. This sometimes led to the right of prior appropriators to obtain as much water as required, with only the remainder becoming available for downstream users. If water becomes scarcer under changing climatic conditions, secure water rights that allow fixed amounts of water withdrawal disincentivise economic water use by rights holders and constrain AOs by non-rights holders from dealing with droughts (Schlager and Heikkila 2011). Removing this barrier to adaptation is not straightforward under the rule of law, which protects property rights. In the presence of secure water rights with fixed water withdrawal, barriers arise as problems of high transaction costs, such as lengthy negotiations, as well as the unproductive effects of organised resistance and rent seeking (cf. Eisenack 2016).

Second, reliance on historical hydrological records is a typical feature of modern water management institutions. There tend to be formalised rules on how data is retrieved and processed, and what statistical models are used for decision making. Important examples are historic runoff data, flooding frequency and data about the hydrological cycle. There are different plausible reasons for such standardised data from an institutional perspective. Hydrological data help to make efficient decisions in complex SESs, such as river basins. Standardisation and provision of hydrological data can help resolving information asymmetries between actors (e.g. upstream and downstream). It might also help in procedures for resolving conflict. However, if the climate is continuously changing over the next decades and centuries, procedures based on hydrological data might become systematically outdated. Established statistical procedures typically use the hydrological record of up to centuries into the past and are based on the assumption that - although river runoff might be highly variable - its statistics (frequency distribution etc.) are stationary. Thus, these statistical procedures might be inappropriate, and even if they are equipped to deal with non-stationary processes, the statistically robust empirical evidence always lags behind. 
Third, slow procedures for institutional change induce path dependency that is relevant to adaptation. Examples include termination dates for water treaties that lie in the far future (Cosens and Williams 2012) or time-consuming procedures of institutional change that involve a multitude of stakeholders and decision-makers in multi-level systems (Farley et al. 2011).

Fourth, established practices of operators and receptors of adaptations, for example long-term appropriation practices of water users, individual complacency and habits of organisational culture, create persistence with regard to behavioural change (Hurlbert and Montana 2015; Kirchhoff et al. 2013).

To sum up these archetypes, path dependency creates barriers because it is generally difficult to change existing institutions, although that might be required because of changing climatic conditions. In our case, change is required in terms of water property rights, hydrological standards, water contracts and habits. Difficulties particularly stem from renegotiating existing arrangements in light of vested interests and transaction costs, or from stalled social learning.

Archetypes related to path dependencies sometimes occur together with those related to uncertainty (e.g. Pulwarty and Melis 2001). First, actors that exercise standardised statistical procedures are not always perfectly informed about the specific character of the river basin that needs to be managed (4.1: see Table 1). Thus, updating extreme event statistics becomes more difficult. Second, uncertainty about the future stimuli of climate change (4.2) hinders adaptations. It might seem to be one straightforward policy option for the data standardisation based on the historical hydrology to be extended by hydrological simulations for climatic conditions that are different from the past. This, however, requires reliable and uncontested climatic projections. These tend to be unavailable from scientific studies.

\section{Zero-sum games}

In zero-sum games, the considered AOs do not allow for Pareto improvements for operators and/or receptors, so that actors are caught in struggles about water services and AOs. In our sample, zero-sum games arise in the presence of two archetypes.

The first archetype are heterogeneous interests of actors about different water services such as freshwater, cooling water, hydro-electricity, navigation, fishing, recreation (3.1). For example, in the Southern Saskatchewan River basin, Canada, divergent interests in water uses for irrigation, industrial purposes, domestic uses and environmental conservation nurtured political stalemates about water management in the face of intensifying droughts (Hurlbert et al. 2009).

Second, negative externalities can be created through an AO (3.2). For example, the planned introduction of water metering was perceived as eroding water rights by agricultural water users in Okanagan, Canada, thus fuelling their opposition (Shepherd et al. 2006). 
In most instances of zero-sum games, barriers arise as problems of high transaction costs. These take the form of organised resistance of water users to AOs, investments in rent-seeking contests or time-consuming conflict resolution processes. If actors mutually invest in wasteful or even destructive conflict activities to win political struggles, zero-sum games of climate change adaptation can transform into downward spirals and lose-lose games. Furthermore, zerosum games frequently interact with other collective action problems. For example, path dependency can co-occur with zero-sum games, as Hamlet (2011) documents for the Columbia River Basin in the US's and Canada's Pacific Northwest, which proposed changes to historical water allocations triggered contentious struggles about water property rights.

\section{Uncertainty}

Although sophisticated scientific climate projections for the next decades and centuries mostly agree on the rough trends of global warming, there is substantial uncertainty about the precise speed of change, about its local manifestation, and about other meteorological variables like precipitation (IPCC 2013). These uncertainties are not simply limitations of current scientific knowledge. They also stem from biophysical processes that are fundamentally difficult to forecast, and from difficulties in predicting human behaviour and socio-economic development over decades. This can lead to an insufficient base for informed decisions. Moreover, uncertainties can also be well employed as an excuse for inaction (Hallegatte 2009).

Interestingly, we can distinguish between two archetypes: uncertainty about climate change (4.2) and uncertainty about the social-ecological system (4.1). The common argument about uncertain climate change only applies to 4.2, but we find 4.1 more frequently (e.g. with lagged information uptake, Pulwarty and Melis 2001, limited informational means to adapt, Farley et al. 2011, or high costs of coordination, Wilder et al. 2010). River basins tend to be inherently complex, so limited knowledge did already arise with a historic and stable climate, and now tends to amplify the problems. This effect has also been observed for adaptation of transport infrastructure (Rotter et al. 2016). In terms of effects on decision making, uncertainty is associated with constrained capacity, insufficient reason, high transaction costs and stalled social learning.

\section{Competing priorities}

In archetypes with competing priorities, the potential operator of an adaptation prioritises objectives other than climate change adaptation, due to concurrent stimuli to the resource system assessed as more urgent than climate change, or due to preferences that are detrimental to the considered AO. Five distinct archetypes are identified that are associated with competing priorities.

First, the operator may face institutional incentives that are incompatible with specific adaptations (5.1). For example, Farley et al. (2011) show for 
water governance along the McKenzie River, USA, that priority to flood control institutionalised in the statute of the water managing agency gave the agency insufficient reason to impacts of flood adaptation for downstream water uses for recreation, fish and wildlife. Second, climate change is rarely the single stimulus to resource systems that water governance needs to adapt to (5.2). These competing priorities for governing water systems include, for instance, increasing water demand resulting from industrial development, the expansion of mining, agriculture and dryland irrigation, tourism and residential development. Third, studies recurrently attributed the prioritisation of non-adaptation objectives to limited awareness of climate change and its local impacts (5.3), as well as to perception of climate change as a problem for future generations (5.4). Finally, competing interests among multiple actors about the priority of adaptation in a river basin can create barriers, for instance through long-term versus shortterm political interests associated with adaptation plans. In the presence of competing priorities, adaptation barriers arise as instances of insufficient reasons of potential operators for climate adaptation. Potential operators under-prioritise adaptations for the benefit of other objectives.

\section{Tangible constraints}

Three archetypical tangible constraints are recurrently identified in our sample: financial constraints (6.1), limited information (6.2), and staff constraints (6.3). Adaptation barriers arise as instances of limited action space that potential operators of adaptation have to plan or implement adaptations. Tangible constraints are often cited as a proximate source of barriers, and they can have underlying collective action problems, for instance if competing priorities or path dependencies constrain the resources available to an operator.

\section{Discussion}

\section{Explaining barriers to climate change adaptation}

Even though the specific manifestations of adaptation barriers in particular cases are heterogeneous, the results have shown that there is a suite of 21 reappearing configurations of attributes. These archetypes give rise to collective action problems generating barriers in decision making for adaptation to changing climatic conditions. It is important to note that this analysis does not take a normative position. Diagnosing one of the barriers does not necessarily imply that it must be resolved. Actors might wish to uphold specific barriers, e.g. to prevent other barriers from popping up such as rent-seeking contests. Instead, the results explain the emergence of adaptation barriers by analysing how each of them is activated by specific factors and specific implications in decision-making processes.

Some barriers are not yet commonly identified in the adaptation literature, while other barriers are well known from other contexts and reconfirmed 
in this meta-analysis (e.g. fragmentation of responsibilities). Examples of the former include the barriers due to non-climatological uncertainty about river basins (4.1), as opposed to the commonly noted uncertainty about climate change (e.g. Biesbroek et al. 2011). The common emphasis on climatological uncertainty might be driven by the strong role of climate projections in adaptation policies that do not yet manifest so frequently in the models for barriers in adaptation governance. If decision-makers have to act based on a limited understanding of social-ecological interactions in the system of concern, the provision of downscaled climate projections might not overcome uncertaintyrelated adaptation barriers. A second, less commonly revealed source of barriers are externalities of AOs that can fuel resistance, power struggles and reinforced inequalities (3.2). While 'fair adaptation' may help overcome barriers associated to externalities, this notion has predominantly been applied to fairness at global scales (e.g. Grasso 2010; Paavola et al. 2006). Future research could analyse the opportunities of 'fair adaptation' to overcome externalities-related barriers in local and national adaptation decision making. Another less commonly identified archetypal barrier relates to vertical coordination gaps (1.3) in contrast to more frequently found horizontal coordination gaps $(1.1,1.2)$. The former contrasts a frequent and normative pro-participation and pro-polycentricity conception (e.g. Gupta et al. 2010; Pahl-Wostl et al. 2012) and invites deeper research about the comparative importance of horizontal and vertical coordination in adaptation governance.

Other 'usual suspects' of commonly reported barriers do not recur in our sample. Examples include the short-termism of public decision making (Heinrichs et al. 2011), missing participation (Biesbroek et al. 2011), linguistic differences between local perspectives and transnational climate change science (Betzold 2015), and insecure land tenure of vulnerable groups (Oberlack and Eisenack 2014). Further interesting archetypical barriers are discussed below in section 5.3.

\section{Methodology}

Any meta-analysis faces limitations, for example potential biases in selecting primary studies. Here, we included scientific literature in English retrieved through keyword-based searches in established databases, Including other languages, databases and grey literature could have expanded the number of primary studies. This could have yielded additional empirical support for the identified archetypes or additional archetypes. However, many reports in the grey literature provide little information about their research methods, theoretical and conceptual foundations and data sources, so they would have been excluded based on the methodological criteria.

Meta-analyses are sometimes criticised for not providing insights on effects that had not been observed before. Inherently, meta-analyses synthesise existing knowledge rather than exploring untested hypotheses. They hence provide a 
bigger picture of the considered phenomenon than the underlying primary studies. They help to identify idiosyncrasy within this bigger picture, and they identify regularities across cases.

Every identified archetype has received empirical support in multiple models and primary studies. This study could not code counterfactuals of the diagnostic attributes because of limited reporting in the primary studies. This is partly due to specific research questions and the analytical focus of the primary studies. It is not the objective to infer causal statements from a sample, but to classify reappearing causal effects identified in the primary studies. They present a synthesis of the positively reported models. The primary studies establish such causal claims for specific cases by methods such as process tracing, comparative analyses, interviews and focus groups that elicit contextualised explanations of adaptation barriers (Meyfroidt 2016). The archetypes can be further tested and refined by searching for, and analysing, cases in which a barrier is not experienced, even though the configuration of diagnostic attributes $D_{i}$ of an archetype $i$ holds. This counterfactual analysis could provide additional support for, or refine, the causal claims of the archetypes.

\section{The institutional economics of climate change adaptation}

The study of climate change adaptation provides a valuable opportunity for scholars to advance CPR theory with regard to how collective action is (not) adapted under changing biophysical conditions (Agrawal 2014). CPR theory shows that dilemmas vary with different biophysical conditions (Janssen and Rollins 2012; Ostrom et al. 1994). By contrast, the results of this paper show that most of the empirically identified barriers to climate adaptation arise out of specific features of institutional history (e.g. fragmented responsibilities or secure property rights in established institutions) and actor attributes (e.g. limited understanding of social-ecological systems) rather than biophysical conditions. This insight needs systematic validation in future empirical research. Although it might be a bias in most authors' contributions synthesised in this metastudy, or in ourselves, there might also be stronger reasons behind it. The primary case studies show that adaptation processes proceed against a historical context of established institutions and socio-political and economic relations. For instance, established property rights constrain AOs by non-rights holders to deal with droughts (Schlager and Heikkila 2011). Further, adapting institutional arrangements might be seen as collective action of a higher order, which is fundamentally different from collective action that deals directly with a problem structure stemming from biophysical conditions (Ostrom 2005). This difference becomes more visible in our study, since we focus on non-static conditions.

While some archetypes are quite straightforward from an economic perspective, others call for more research from an institutional angle. Problems of missing incentives (or insufficient reason) reflect only partly the diversity of encountered adaptation barriers. An interesting example is the trade-off between 
the institutional adaptability and institutional stability of hydrological standards required for planning, accountability and compliance (2.2). Standardisation procedures play an important role in light of uncertainty. They are important for dealing with asymmetric information and legitimising collective decisions. On the other hand, they can create a detrimental path dependency if conditions change. Further important questions are raised by secure property rights with fixed allocations under changing hydrological conditions (2.1). Building on institutional analysis on this matter (e.g. Schlager and Heikkila 2011), the policy question needs attention: how can property rights arrangements be adapted to new climatic conditions in light of existing claims and vested interests?

Taken together, CPR theory is advancing our ability to diagnose the precise structure of adaptation barriers. This ongoing process requires expanded research to arrive at a more comprehensive understanding how configurations of biophysical, institutional, socio-political and economic attributes create specific collective action barriers to climate adaptation, and how particular opportunities enable actors to prevent, alleviate or overcome particular barriers in particular contexts.

\section{Conclusions}

This paper has analysed 26 systematically selected and coded empirical publications of adapting water governance in river basins to climate change. Despite the huge heterogeneity of cases, the meta-analysis identifies recurrent barriers to adaptation. Each archetype is activated by specific diagnostic attributes, as shown in section 4 . In particular, these findings underpin the need to give strong consideration to the crucial difficulties with water property rights, hydrological standards, externalities caused by AOs, non-climatological uncertainty and lack of vertical coordination. Generally, the catalogue of archetypes contributes to the urgently needed literature on explaining barriers to adaptation more thoroughly, here from a comparative institutional analysis perspective.

We propose archetypes as a methodological approach to advance the study of institutional diversity, and the paper illustrates its scope for comparative studies that have to deal with substantial case heterogeneity. The approach seems well suited to develop middle-range theories of institutional diversity (Merton [1949] 1968; Ostrom 2005), because it allows us to identify and explain different patterns for different subsets of cases. Table 1 shows how different institutional features give rise to different barriers to adapting collective action in the face of climate change. We thus think that the archetype approach adds a promising tool to the portfolio of comparative institutional analysis. The approach can be applied to identify theoretical building blocks from larger case study collections (e.g. Cox 2014; Hinkel et al. 2015) in a rigorous way. The focus on coding models rather than cases makes it easier to deal with variables that are not 
jointly reported in a case study sample. As a further innovation, archetypes accept partial theories that can be combined as building blocks to diagnose single cases. Both make the approach suitable for dealing with considerable case heterogeneity.

The analysis contributes to a diagnostic approach to institutional analysis that seeks to explain collective action arrangements, in particular from biophysical conditions (Cox 2011; Ostrom et al. 2007; Young 2002). Important steps towards institutional diagnostics for the governance of CPRs have been made by organising the multitude of relevant variables into multi-tiered frameworks, such as the SES framework (Ostrom 2009), that balance biophysical and socioeconomic explananda. Our results show that a prevalent focus on biophysical attributes alone may overlook the importance of pre-existing institutions and socio-political relations in explaining collective action in dynamic biophysical environments.

Future research on institutional change might take climate change impacts on water governance as a particularly relevant study context. Dynamic exogenous conditions might challenge the stability of property rights, and the legitimacy of standards for collective decision making under uncertainty might erode. Future research on barriers to adaptation can start from the proposed list of archetypes to test and refine it in focused empirical studies. By extending the outcome attributes to opportunities for adaptation, a crucial next step is to match governance strategies to specific archetypical barriers to analyse how they may prevent, alleviate or overcome barriers in different contexts.

\section{Acknowledgements}

We thank Edella Schlager for helpful discussions on collective action dilemmas at the 2016 SESYNC workshop 'Breaking the Code'; the reviewers for their useful comments that strengthened the paper; and Anastasiia Gotgelf and Julia Tschersich for research assistance.

\section{References}

Note: References to the publications included in the meta-analysis are provided in the appendix.

Agrawal, A. (2014), 'Studying the commons, governing common-pool resource outcomes: some concluding thoughts', Environmental Science \& Policy 36: 86-91.

Barnett, J., L. S. Evans, G. Gross, A. S. Kiem, R. T. Kingsford, J. P. Palutikof, C. M. Pickering and S. G. Smithers (2015), 'From barriers to limits to climate change adaptation: path dependency and the speed of change', Ecology and Society, 20(3): 5.

Berkhout, F., J. Hertin and D. M. Gann (2006), 'Learning to adapt: organisational adaptation to climate change impacts', Climatic Change, 78(1): 135-56.

Betzold, C. (2015) 'Adapting to climate change in small island developing states', Climatic Change, 133(3): 481-9. 
Biesbroek, G. R., J. E. M. Klostermann, C. J. A. M. Termeer and P. Kabat (2011), 'Barriers to climate change adaptation in the Netherlands', Climate Law, 2: 181-99.

Biesbroek, G. R., J. E. M. Klostermann, C. J. A. M. Termeer and P. Kabat (2013), 'On the nature of barriers to climate change adaptation', Regional Environmental Change, 13(5): 1119-29.

Biesbroek, G. R., C. J. A. M. Termeer, J. E. Klostermann and P. Kabat (2014), 'Rethinking barriers to adaptation: mechanism-based explanation of impasses in the governance of an innovative adaptation measure', Global Environmental Change, 26: 108-18.

Bisaro, A. and J. Hinkel (2016), 'Governance of social dilemmas in climate change adaptation', Nature Climate Change, 6: 354-9.

Blomquist, W. A., A. Dinar and K. Kemper (2005), 'Comparison of institutional arrangements for river basin management in eight basins', World Bank Policy Research Working Paper, No. 3636.

Bromley, D. W. (2006), Sufficient reason: Volitional pragmatism and the meaning of economic institutions. Princeton, Oxford: Princeton University Press.

Ching, L. and M. Mukherjee (2015), 'Managing the socio-ecology of very large rivers: collective choice rules in IWRM narratives', Global Environmental Change, 34: 17284.

Cosens, B. A. and M. K. Williams (2012), 'Resilience and water governance: adaptive governance in the Columbia River basin', Ecology and Society, 17(4): 3.

Cox, M. (2011), 'Advancing the diagnostic analysis of environmental problems', International Journal of the Commons, 5(2): 346-63.

Cox, M. (2014), 'Understanding large social-ecological systems: introducing the SESMAD project', International Journal of the Commons, 8(2): 265-76.

Cox, M., G. Arnold and S. Villamayor-Tomas (2010), 'A review of design principles for community-based natural resource management', Ecology and Society, 15(4): 38-6.

Eisenack, K. (2012), 'Archetypes of adaptation to climate change', in M. Glaser, G. Krause, B. M. W. Ratter and M. Welp (eds), Human/Nature Interactions in the Anthropocene: Potentials of Social-Ecological Systems Analysis, New York, NJ: Routledge, pp. 10722.

Eisenack, K. (2016), 'Institutional adaptation to cooling water scarcity in the electricity sector under global warming', Ecological Economics, 124: 153-63.

Eisenack, K., M. Lüdeke and J. Kropp (2006), 'Construction of archetypes as a formal method to analyze social-ecological systems', Proceedings of the Institutional Dimensions of Global Environmental Change Synthesis Conference, Bali.

Eisenack, K., S. Moser, E. Hoffmann, R. Klein, C. Oberlack, A. Pechan, M. Rotter and C. J. A. M. Termeer (2014), 'Explaining and overcoming barriers to climate change adaptation', Nature Climate Change, 4: 867-72.

Eisenack, K. and R. Stecker (2012), 'A framework for analyzing climate change adaptations as actions', Mitigation and Adaptation Strategies for Global Change, 17(3): 243-60.

Eisenack, K., R. Stecker, D. Reckien, and E. Hoffmann (2011), 'Adaptation to climate change in the transport sector: a review of actions and actors', Mitigation and Adaptation Strategies for Global Change, 17(5): 451-69.

Farley, K. A., C. Tague and G. E. Grant (2011), 'Vulnerability of water supply from the Oregon Cascades to changing climate: linking science to users and policy', Global Environmental Change, 21(1): 110-22.

Frey, U. and M. Cox (2015), 'Building a diagnostic ontology of social-ecological systems', International Journal of the Commons, 9(2): 595-618. 
Ganter, B and R. Wille (1999), Formal Concept Analysis: Mathematical Foundations, Berlin, Heidelberg: Springer.

Garrelts, H. and H. Lange (2011), 'Path dependencies and path change in complex fields of action: climate adaptation policies in Germany in the realm of flood risk management', Ambio, 40(2): 200-9.

Garrick, D., S. M. Whitten and A. Coggan (2013), 'Understanding the evolution and performance of water markets and allocation policy: a transaction costs analysis framework', Ecological Economics, 88: 195-205.

Grasso, M. (2010), 'An ethical approach to climate adaptation finance', Global Environmental Change, 20(1): 74-81.

Gupta, J., C. J. A. M. Termeer, J. Klostermann, S. Meijermink, M. van den Brink, P. Jong, S. G. Nooteboom and E. Bergsma (2010), 'The adaptive capacity wheel: a method to assess the inherent characteristics of institutions to enable the adaptive capacity of society', Environmental Science \& Policy, 13(6): 459-471.

Hallegatte, S. (2009) 'Strategies to adapt to an uncertain climate change', Global Environmental Change, 19(2): 240-7.

Hamlet, A. F. (2011), 'Assessing water resources adaptive capacity to climate change impacts in the Pacific Northwest Region of North America', Hydrology and Earth System Sciences, 15(5): 1427-43.

Heikkila, T., E. Schlager and M. W. Davis (2011), 'The role of cross-scale institutional linkages in common pool resource management: assessing interstate river compacts', Policy Studies Journal, 39(1), 121-45.

Heinrichs, D., R. Aggarwal, J. Barton, E. Bharucha, C. Butsch, M. Fragkias, P, Johnston, F. Kraas, K. Krellenberg, A. Lampis, O. G. Ling, J. Vogel (2011), 'Adapting cities to climate change: opportunities and constraints', in D. Hoornweeg, M. Freire, M. J. Lee, P. Bhada-Tata, B. Yuen, (Eds), Cities and Climate Change: Responding to an Urgent Agenda, Washington, USA: World Bank, pp. 193-224.

Hill, M. (2013), 'Adaptive capacity of water governance: cases from the Alps and the Andes', Mountain Research and Development, 33(3): 248-59.

Hinkel, J.; M. Cox; M. Schlüter; C. Binder and T. Falk (2015), 'A diagnostic procedure for applying the social-ecological systems framework in diverse cases', Ecology and Society, 20(1): 32 .

Huitema, D., W. N. Adger, F. Berkhout, E. Massey, D. Mazmanian, S. Munaretto, R. Plummer and C. J. A. M. Termeer (2016), 'The governance of adaptation: choices, reasons, and effects: introduction to the special feature', Ecology and Society, 21(3): 37.

Huntjens, P., L. Lebel, C. Pahl-Wostl, R. Schulze, J. Camkin and N. Kranz (2012), 'Institutional design propositions for the governance of adaptation to climate change in the water sector', Global Environmental Change, 22(1): 67-81.

Hurlbert, M. A. and H. Diaz, (2013), 'Water governance in Chile and Canada: a comparison of adaptive characteristics', Ecology and Society, 18(4): 61-83.

Hurlbert, M. and E. Montana (2015) 'Dimensions of adaptive water governance and drought in Argentina and Canada', Journal of Sustainable Development, 8(1): 120-37.

Hurlbert, M., H. Diaz, D. R. Corkal and J. Warren (2009), 'Climate change and water governance in Saskatchewan, Canada', International Journal of Climate Change Strategies and Management, 1(2): 118-32.

IPCC (2013), 'Summary for Policymakers'. In T. F. Stocker, D. Qin, G.-K. Plattner, M. Tignor, S. K. Allen, J. Boschung, A. Nauels, Y. Xia, V. Bex, P. M. Midgley (eds), Climate Change 2013: The Physical Science Basis. Contribution of Working Group I to the Fifth 
Assessment Report of the Intergovernmental Panel on Climate Change. Cambridge, UK, New York, USA: Cambridge University Press.

Janssen, M. A. and N. D. Rollins (2012). 'Evolution of cooperation in asymmetric commons dilemmas', Journal of Economic Behavior and Organization, 81(1): 220-9.

Kirchhoff, C. J., M. C. Lemos and N. L. Engle (2013), 'What influences climate information use in water management? The role of boundary organizations and governance regimes in Brazil and the U.S', Environmental Science \& Policy, 26: 6-18.

Klein, R. J. T. and S. Juhola (2014), 'A framework for Nordic actor-centered adaptation research', Environmental Science \& Policy, 40: 101-15.

Knieper, C. and C. Pahl-Wostl (2016), 'A comparative analysis of water governance, water management, and environmental performance in river basins', Water Resources Management', 30(7): 2161-77.

Kok, M., M. Lüdeke, P. Lucas, T. Sterzel, C. Walther, P. Janssen, D. Sietz and I. de Soysa (2016), 'A new method for analysing socio-ecological patterns of vulnerability', Regional Environmental Change, 16(1): 229-43.

Libecap, G. D. (2011), 'Institutional path dependence in climate adaptation: Coman's "Some unsettled problems of irrigation"', American Economic Review, 101: 64-80.

Lüdeke, M. K. B., G. Petschel-Held and H. J. Schellnhuber (2004), 'Syndromes of global change: the first panoramic view', GAIA, 13(1): 42-9.

Meinzen-Dick, R. (2007). 'Beyond panaceas in water institutions', Proceedings of the National Academy of Sciences, 104(39): 15,200-5.

Milman, A., L. Bunclark, D. Conway and W. N. Adger (2013), 'Assessment of institutional capacity to adapt to climate change in transboundary river basins', Climatic Change, 121(4): 755-70.

Merton, R. K. ([1949]1968), Social Theory and Social Structure, New York: Free Press.

Meyfroidt, P. (2016), 'Approaches and terminology for causal analysis in land systems science', Journal of Land Use Science, 11(5): 501-22.

Moser, S. C. and J. A. Ekstrom (2010), 'A framework to diagnose barriers to climate change adaptation', PNAS, 107(51): 22,026-31.

Næss, L. O., G. Bang, S. Eriksen and J. Vevatne (2005), 'Institutional adaptation to climate change: flood responses at the municipal level in Norway', Global Environmental Change, 15(2): 125-38.

Oberlack, C. (2017), 'Diagnosing institutional barriers and opportunities for adaptation to climate change', Mitigation and Adaptation Strategies for Global Change, 22(5): 80538.

Oberlack, C. and K. Eisenack (2014), 'Alleviating barriers to urban climate change adaptation through international cooperation', Global Environmental Change, 24: 349-62.

Oberlack, C., L. Tejada, P. Messerli, S. Rist and M. Giger (2016), 'Sustainable livelihoods in the global land rush? Archetypes of livelihood vulnerability and sustainability potentials', Global Environmental Change, 41: 153-71.

Ostrom, E. (1990), Governing the Commons, Cambridge: Cambridge University Press.

Ostrom, E. (2005), Understanding Institutional Diversity, Princeton, NJ: Princeton University Press.

Ostrom, E. (2009), 'A general framework for analyzing sustainability of social-ecological systems', Science, 325(5939): 419-22.

Ostrom, E. and R. Gardner (1993) 'Coping with asymmetries in the commons: self-governing irrigation systems can work', Journal of Economic Perspectives 7(4): 93-112. 
Ostrom, E., R. Gardner and J. Walker (1994) Rules, Games, and Common-pool Resources, Michigan: University of Michigan Press.

Ostrom, E., M. A. Janssen and J. Anderies (2007), 'Going beyond panaceas', Proceedings of the National Academy of Sciences, 104(39): 15,176-8.

Paavola, J. (2007), 'Institutions and environmental governance: a reconceptualization', Ecological Economics 63(1): 93-103.

Paavola, J. and W. N. Adger (2006) 'Fair adaptation to climate change', Ecological Economics, 56(4): 594-609.

Pahl-Wostl, C. (2009), 'A conceptual framework for analysing adaptive capacity and multilevel learning processes in resource governance regimes', Global Environmental Change, 19(3): 354-65.

Pahl-Wostl, C. and C. Knieper (2014), 'The capacity of water governance to deal with the climate change adaptation challenge: using fuzzy set qualitative comparative analysis to distinguish between polycentric, fragmented and centralized regimes', Global Environmental Change, 29: 139-54.

Pahl-Wostl, C., L. Lebel, C. Knieper and E. Nikitina (2012), 'From applying panaceas to mastering complexity: toward adaptive water governance in river basins', Environmental Science \& Policy, 23: 24-34.

Petschel-Held, G. (2003), Integrative Forschung zwischen Normativität und Unsicherheit, Nomothese und Idiographie in den Nachhaltigkeitswissenschaften. In N. GottschalkMazouz and N. Mazouz (eds), Nachhaltigkeit und globaler Wandel Campus, Frankfurt, Germany, New York, USA, pp. 277-97.

Pulwarty, R. S. and R. Maia (2015), 'Adaptation challenges in complex rivers around the world: the Guadiana and the Colorado basins', Water Resources Management, 29(2): 273-93.

Pulwarty, R. S. and T. S. Melis (2001), 'Climate extremes and adaptive management on the Colorado River: lessons from the 1997-8 ENSO event', Journal of Environmental Management, 63(3): 307-24.

Ragin, C. C. (1987), The Comparative Method, Oakland: University of California Press.

Rittel, J. H. W. and M. M. Webber (1973), 'Dilemmas in a general theory of planning', Policy Science, 4(2): 155-69.

Roggero, M. (2015), Adapting institutions: exploring climate adaptation through institutional economics and set relations, Ecological Economics, 118: 114-22.

Rotter, M., E. Hoffmann, A. Pechan and R. Stecker (2016), 'Competing priorities: how actors and institutions influence adaptation in the German railway system, Climatic Change, 137(3): 609-23.

Rudel, T. (2008), 'Meta-analyses of case studies: a method for studying regional and global environmental change', Global Environmental Change, 18(1): 18-25.

Saleth, M. and A. Dinar (2008), 'Linkages within institutional structure: an empirical analysis of water institutions', Journal of Institutional Economics, 4(3): 375-401:

Schlager, E. and T. Heikkila (2011), 'Left high and dry? Climate change, commonpool resource theory, and the adaptability of Western water compacts', Public Administration Review, 71(3): 461-70.

Schneider, C. Q. and C. Wagemann (2012), Set-theoretic Methods for the Social Sciences, Cambridge: Cambridge University Press.

Schmid, A. A. (2004), Conflict and Cooperation: Institutional and Behavioral Economics, Oxford: Blackwell. 
Shepherd, P., J. Tansey and H. Dowlatabadi (2006), 'Context matters: what shapes adaptation to water stress in the Okanagan?' Climatic Change, 78(1): 31-62.

Sietz, D. and H. van Dijk (2015), 'Land-based adaptation to global change: what drives soil and water conservation in western Africa?’ Global Environmental Change, 33(2): 131-41.

Sietz, D., M. K. B. Lüdeke and C. Walther (2011), 'Categorisation of typical vulnerability patterns in global drylands', Global Environmental Change, 21(2): 431-40.

Tompkins, E. L. and H. Eakin (2012) 'Managing private and public adaptation to climate change', Global Environmental Change, 22(1): 3-11.

Vatn, A. (2005), Institutions and the Environment, Edward Elgar, Cheltenham, UK.

Villamayor-Tomas, S., P. Grundmann, G. Epstein, T. Evans and C. Kimmich (2015) 'The water-energy-food security nexus through the lenses of the value chain and the institutional analysis and development frameworks', Water Alternatives, 8(1): 735-55.

UNEP (2007), Global Environmental Outlook 4. United Nations Environment Programme. Valetta, Malta: Progress Press.

Warren, A. (2002), 'Land degradation is contextual', Land Degradation and Development, 13(6): 449-59.

WBGU (1994), World in Transition: Basic Structure of Global People-Environment Interactions, Bonn: Economica Verlag.

Wilder, M., C. A. Scott, N. P. Pablos, R. G. Varady, G. M. Garfin and J. McEvoy (2010), 'Adapting across boundaries: climate change, social learning, and resilience in the USMexico border region', Annals of the Association of American Geographers, 100(4): 917-28.

Williamson, O. E. (2010), 'Transaction cost economics: the natural progression', American Economic Review, 100(3): 673-90.

Young, O. R. (2002), The Institutional Dimensions of Environmental Change: Fit, Interplay, and Scale, London, Cambridge: MIT Press. 


\section{Appendix}

Table A1: Primary studies, regions, river basins and archetypes

\begin{tabular}{|c|c|c|c|}
\hline Article & Countries & River basins & Archetypes \\
\hline Binder 2006 & USA & Watersheds in Washington State & $1.4 ; 2.4 ; 3.1 ; 4.2 ; 6.1 ; 6.2$ \\
\hline Boer 2010 & Australia & Catchments in northeast Queensland & $1.5 ; 2.1 ; 2.2 ; 3.1 ; 3.2 ; 5.2$ \\
\hline Cosens and Williams 2012 & Canada, USA & Columbia River & $1.1 ; 4.2$ \\
\hline Cots et al. 2009 & Portugal, Spain & Guadiana River & $5.4 ; 5.5$ \\
\hline Engle and Lemos 2010 & Brazil & 18 river basins ( 4 in-depth) & $1.3 ; 3.1 ; 5.5$ \\
\hline Farley et al. 2011 & USA & McKenzie River & $1.1 ; 1.5 ; 3.1 ; 3.2 ; 4.1 ; 4.2 ; 5.1 ; 5.5$ \\
\hline Hamlet 2011 & USA & Columbia River & $1.1 ; 1.2 ; 2.2 ; 2.4 ; 3.1 ; 3.2 ; 4.1 ; 6.2 ; 6.3$ \\
\hline Hill 2013 & Chile, Switzerland & Aconcagua (Chile), Rhone $(\mathrm{CH})$ & $1.3 ; 1.4 ; 1.5 ; 5.3 ; 5.4 ; 6.2$ \\
\hline Hill-Clarvis and Allan 2014 & Chile & Aconcagua & $1.4 ; 2.1 ; 2.2 ; 4.1 ; 6.1$ \\
\hline Hurlbert and Diaz 2013 & Canada, Chile & Southern Saskatchewan (Canada), Elqui (Chile) & $1.1 ; 1.5 ; 3.1 ; 4.2 ; 5.1 ; 6.1 ; 6.2 ; 6.3$ \\
\hline Hurlbert and Montana 2015 & Argentina, Canada & Mendoza (Argentina), Oldman River (Canada) & $1.1 ; 1.2 ; 1.3 ; 2.4 ; 5.3 ; 6.1$ \\
\hline Hurlbert et al. 2009 & Canada & Southern Saskatchewan & $1.1 ; 3.1 ; 5.5$ \\
\hline Kirchhoff et al. 2013 & Brazil, USA & $\begin{array}{l}\text { Jaguaribe-Banabuiu Basin, Itajai Basin (Brazil), } \\
\text { watersheds in Arizona and Georgia (USA) }\end{array}$ & $1.1 ; 1.2 ; 1.4 ; 2.3 ; 2.4 ; 5.1 ; 5.2 ; 5.3 ; 6.1$ \\
\hline Krysanova et al. 2010 & Multiple & $\begin{array}{l}\text { Elbe, Guadiana, Rhine, Nile, Orange, } \\
\text { Amudarya }\end{array}$ & $1.2 ; 1.4 ; 3.1 ; 4.1 ; 4.2 ; 5.2 ; 5.4 ; 6.1$ \\
\hline Larsen 2011 & Denmark & Multiple rivers & $4.2 ; 5.5$ \\
\hline O’Connor et al.1999 & USA & Susquehanna River & 5.3 \\
\hline Pittock and Finlayson 2013 & Australia & Murray-Darling Basin & $2.4 ; 3.2$ \\
\hline Pulwarty and Maia 2015 & $\begin{array}{l}\text { Mexico, Portugal, Spain, } \\
\text { USA }\end{array}$ & $\begin{array}{l}\text { Colorado River (Mexico/USA), Guadiana } \\
\text { (Portugal/Spain) }\end{array}$ & $1.2 ; 2.3 ; 3.1 ; 3.2$ \\
\hline Pulwarty and Melis 2001 & Mexico, USA & Colorado River & $2.2 ; 4.1 ; 4.2$ \\
\hline Shepherd et al. 2006 & Canada & Okanagan & $1.3 ; 1.4 ; 2.1 ; 3.2$ \\
\hline Singh-Peterson et al. 2013 & Australia & Tweed River & $1.1 ; 3.1$ \\
\hline Wei et al. 2011 & Australia & Murray-Darling & $3.1 ; 4.1 ; 5.1$ \\
\hline Welsh et al. 2013 & USA & Bear river basin & 5.3 \\
\hline Wilder et al. 2010 & Mexico, USA & Arizona-Sonora region & $1.2 ; 3.1 ; 4.1 ; 6.1 ; 6.3$ \\
\hline
\end{tabular}




\section{References of included primary studies}

Binder, L. C. W. (2006), 'Climate change and watershed planning in Washington state', Journal of the American Water Resources Association, 42(4): 915-26.

Boer, H. (2010), 'Policy options for, and constraints on, effective adaptation for rivers and wetlands in northeast Queensland', Australasian Journal of Environmental Management, 17(3): 154-64.

Cosens, B. A. and M. K. Williams (2012), 'resilience and water governance: adaptive governance in the Columbia River basin', Ecology and Society, 17(4): 3.

Cots, F., J. D. Tàbara, D. McEvoy, S. Werners and E. Roca (2009), 'Cross-border organisations as an adaptive water management response to climate change: the case of the Guadiana River basin', Environment and Planning C, 27(5): 876-93.

Engle, N. L. and M. C. Lemos (2010), 'Unpacking governance: building adaptive capacity to climate change of river basins in Brazil', Global Environmental Change, 20(1): 4-13.

Farley, K. A., C. Tague and G. E. Grant (2011), 'Vulnerability of water supply from the Oregon Cascades to changing climate: linking science to users and policy', Global Environmental Change, 21(1): 110-22.

Gillon, S., E. G. Booth and A. R. Rissman (2015), 'Shifting drivers and static baselines in environmental governance: Challenges for improving and proving water quality outcomes', Regional Environmental Change, 16(3): 759-75.

Hamlet, A. F. (2011), 'Assessing water resources adaptive capacity to climate change impacts in the Pacific Northwest Region of North America', Hydrology and Earth System Sciences, 15(5): 1427-43.

Hill, M. (2013), 'Adaptive capacity of water governance: cases from the Alps and the Andes', Mountain Research and Development, 33(3): 248-59.

Hill-Clarvis, M. and A. Allan (2014), 'Adaptive capacity in a Chilean context: A questionable model for Latin America', Environmental Science \& Policy, 43: 78-90.

Hurlbert, M., H. Diaz, D. R. Corkal and J. Warren (2009), 'Climate change and water governance in Saskatchewan, Canada', International Journal of Climate Change Strategies and Management, 1(2): 118-32.

Hurlbert, M. A. and H. Diaz (2013), 'Water governance in Chile and Canada: a comparison of adaptive characteristics', Ecology and Society, 18(4): 61-83.

Hurlbert, M. A. and E. Montana (2015), 'Dimensions of adaptive water governance and drought in Argentina and Canada', Journal of Sustainable Development, 8(1): 12037.

Kirchhoff, C. J., M. C. Lemos and N. L. Engle (2013), 'What influences climate information use in water management? The role of boundary organizations and governance regimes in Brazil and the US', Environmental Science \&o Policy, 26: 6-18.

Kistin, E.J. and P. J. Ashton (2008), 'Adapting to change in transboundary rivers: an analysis of treaty flexibility on the Orange-Senqu River basin', International Journal of Water Resources Development, 24(3): 385-400.

Krysanova, V., C. Dickens, J. Timmerman, C. Varela-Ortega, M. Schlüter, K. Roest, P. Huntjens, F. Jaspers, H. Buiteveld, E. Moreno, J. de Pedraza Carrera, R. Slámová, M. Martínková, I. Blanco, P. Esteve, K. Pringle, C. Pahl-Wostl and P. Kabat (2010), 'Cross-comparison of climate change adaptation strategies across large river basins in Europe, Africa and Asia', Water Resources Management, 24(14): 4121-60.

Larsen, S. V. (2011), 'Risk as a challenge in practice: investigating climate change in water management', Regional Environmental Change, 11(1): 111-22. 
O’Connor, R. E., B. Yarnal, R. Neff, R. Bord, N. Wiefek, C. Reenock, R. Shudak, C. L. Jocoy, P. Pascals and C. G. Knight (1999), 'Weather and climate extremes, climate change, and planning: views of community water system managers in Pennsylvania's Susquehanna River basin', Journal of the American Water Resources Association, 35(6): 1411-9.

Pittock, J. and C. M. Finlayson (2013), 'Climate change adaptation in the Murray-Darling Basin: reducing resilience of wetlands with engineering', Australian Journal of Water Resources, 12(2): 161-9.

Pulwarty, R. S. and R. Maia (2015), 'Adaptation challenges in complex rivers around the world: the Guadiana and the Colorado basins', Water Resources Management, 29(2): 273-93.

Pulwarty, R. S. and T. S. Melis (2001), 'Climate extremes and adaptive management on the Colorado River: lessons from the 1997-1998 ENSO event', Journal of Environmental Management, 63(3): 307-24.

Shepherd, P., J. Tansey and H. Dowlatabadi (2006), 'Context matters: what shapes adaptation to water stress in the Okanagan?' Climatic Change, 78(1): 31-62.

Singh-Peterson, L., S. Serrao-Neumann, F. Crick and I. Sporne (2013), 'Planning for climate change across borders: insights from the Gold Coast (QLD) - Tweed (NSW) region', Australian Planner, 50(2):148-56.

Wei, Y., J. Langford, I. R. Willett, S. Barlow and C. Lyle (2011), 'Is irrigated agriculture in the Murray Darling Basin well prepared to deal with reductions in water availability?' Global Environmental Change, 21(3): 906-16.

Welsh, L. W., J. Endter-Wada, R. Downard and K. M. Kettenring (2013), 'Developing adaptive capacity to droughts: the rationality of locality', Ecology and Society, 18(2): 7.

Wilder, M., C. A. Scott, N. P. Pablos, R. G. Varady, G. M. Garfin and J. McEvoy (2010), 'Adapting across boundaries: climate change, social learning, and resilience in the USMexico border region', Annals of the Association of American Geographers, 100(4): 917-28. 